\title{
Qualidade microbiológica e índice de segurança de fórmulas infantis preparadas em lactário hospitalar
}

\author{
Deborah R. Siqueira, ${ }^{1,2 \star}$ Maria L. M. Lopes, ${ }^{3}$ Silvia M. C. Garcia ${ }^{4}$
}

\section{Resumo}

Introdução: As doenças transmitidas por alimentos são consideradas um problema de saúde pública eminente e são causadas por ingestão de alimento ou água contaminada. Objetivos: O objetivo deste estudo foi avaliar a qualidade microbiológica e o índice de segurança de fórmulas infantis preparadas no lactário. Métodos: Foram analisadas 28 amostras de água utilizadas para reconstituição de fórmulas em pó e 28 amostras de fórmulas infantis reconstituídas. O índice de segurança (IS) foi calculado com base na análise das temperaturas da água de reconstituição e da geladeira de conservação das fórmulas reconstituídas, considerando como meta os parâmetros de temperaturas propostos pelas legislações específicas. Resultados: As amostras de água apresentaram ausência de coliformes a $35^{\circ} \mathrm{C} /$ mL e contagem de bactérias aeróbias mesófilas totais abaixo dos limites permitidos pela legislação. As amostras de fórmulas infantis reconstituídas apresentaram ausência de coliformes a $45^{\circ} \mathrm{C}$, estafilococos coagulase positiva e Salmonella sp e para coliformes a $35^{\circ} \mathrm{C}$ as amostras não ultrapassaram os valores permitidos pela legislação. As temperaturas médias da água nos turnos manhã e tarde foram, respectivamente, $89^{\circ} \mathrm{Ce} 91,5^{\circ} \mathrm{Ce}$ o IS foi de 0,98 . As temperaturas médias da geladeira foram 2,5 ${ }^{\circ} \mathrm{C}$ e $3,1^{\circ} \mathrm{C}$ e IS de 0,99. Conclusões: Evidenciou-se que, tanto as amostras de água como as amostras de fórmulas infantis estavam adequadas para o consumo humano. O IS obtido revelou grau satisfatório de cumprimento das exigências da legislação vigente. O monitoramento destas etapas é fundamental para garantia da qualidade das fórmulas produzidas.

Descritores: Segurança alimentar e nutricional; Conservação de alimentos.

\section{Abstract \\ Microbiological quality and safety index of infant formulas prepared in hospital lactaria}

Introduction: Foodborne illnesses are considered an imminent public health problem and are caused by ingestion of contaminated food or water. Objectives: The objective of this study was to evaluate the microbiological quality and the safety level of infant formulas prepared in a hospital milk dispensary. Methods: The study analized 28 water samples used for reconstitution of powdered formulas and 28 samples of reconstituted infant formulas. The Safety Index (SI) was calculated based on the analysis of the temperatures of the water used in the reconstitution of infant formulas and the refrigerator used for storage of reconstituted infant formulas, considering as goal the temperature parameters proposed by specific legislations.
1. Divisão de Nutrição. Hospital Universitário Pedro Ernesto. Universidade do Estado do Rio de Janeiro. Rio de Janeiro. Rio de Janeiro, RJ, Brasil.

2. Programa de Pós-graduação em Nutrição Clínica. Instituto de Nutrição Josué de Castro. Universidade Federal do Rio de Janeiro. Rio de Janeiro. Rio de Janeiro, RJ, Brasil.

3. Departamento de Nutrição Básica e Experimental. Universidade Federal do Rio de Janeiro. Instituto de Nutrição Josué de Castro. Rio de Janeiro. Rio de Janeiro, RJ, Brasil.

4. Departamento de Nutrição e Dietética. Universidade Federal do Rio de Janeiro. Instituto de Nutrição Josué de Castro. Rio de Janeiro. Rio de Janeiro, RJ, Brasil.

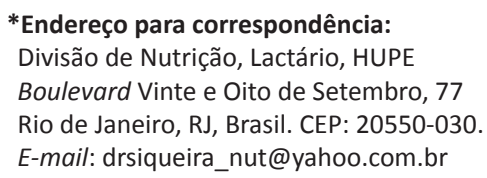

Results: Water samples showed absence of coliforms at $35^{\circ} \mathrm{C} /$ $\mathrm{mL}$ and counts of total mesophilic aerobic bacteria below the values allowed by the legislation. The samples of reconstituted infant formulas were absent for coliforms at $45^{\circ} \mathrm{C}$, coagulase positive staphylococci and Salmonella sp. Coliforms at $35^{\circ} \mathrm{C}$ samples did not exceed the values allowed by the legislation. The mean water temperatures in the morning and afternoon shifts were respectively $89^{\circ} \mathrm{C}$ and $91.5^{\circ} \mathrm{C}$ and the IS was 0.98 . The average temperatures of the refrigerator were $2.5^{\circ} \mathrm{C}$ and $3.1^{\circ} \mathrm{C}$ and IS of 0.99 . Conclusions: Our results showed that the water and infant formulas samples were suitable for human consumption. TheSI obtained revealed a satisfactory degree of compliance with the requirements of the current legislation. The monitoring of these steps is fundamental to guarantee the quality of the formulas produced.

Keywords: Food and nutrition security; Food preservation.

\section{Resumen}

Calidad microbiológica y índice de seguridad de fórmulas infantiles preparadas en lactario hospitalario

Introducción: las enfermedades transmitidas por los alimentos se consideran un importante problema de salud pública y son 


\section{Artigo original}

causadas por la ingestión de alimentos o agua contaminados. Objetivos: El objetivo de este estudio fue evaluar la calidad microbiológica y el nivel de seguridad de la fórmula infantil preparada en el dispensario de leche de un hospital. Métodos: Se analizaron 28 muestras de agua para la reconstitución de fórmulas en polvo y 28 muestras de fórmula infantil fueron reconstituidas. El índice de seguridad (IS) se calculó en base al análisis de las temperaturas del agua usada en la reconstitución de fórmulas infantiles y el refrigerador utilizado para el almacenamiento de fórmulas infantiles reconstituidas, considerando como un objetivo los parámetros de temperatura propuestos por leyes específicas. Resultados: Las muestras de agua mostraron ausencia de coliformes a $35^{\circ} \mathrm{C} / \mathrm{ml}$, y recuento de bacterias aerobias mesófilas debajo de los límites permitidos por la ley. Las muestras de fórmulas infantiles reconstituidas

\section{Introdução}

As doenças transmitidas por alimentos (DTA) são consideradas um problema de saúde pública eminente e são causadas por ingestão de alimento ou água contaminada. No Brasil, no período de 2007 a julho de 2016, houve cerca de 6.632 surtos de DTA e 109 óbitos, sendo identificados a água, o leite e derivados como tendo, respectivamente, 563 e 356 casos nesse período. Os principais agentes etiológicos associados aos surtos eram Salmonella, E.colie S. aureus, representando 90,5\% dos microrganismos envolvidos. Os sinais e sintomas mais evidentes eram diarreia $(29,6 \%)$ e dor abdominal $(19,6 \%)$. As regiões Sul e Sudeste, em 2016, lideraram o histórico com mais notificações nos casos de DTA, com percentuais de 24,8 e $43,8 \%$, respectivamente. Dentre os locais de ocorrência de surtos de DTA, os hospitais e unidades de saúde representam 3,7\%. Por diversos fatores, muitos casos de DTA, não são notificados, inviabilizando a identificação da gravidade do problema. ${ }^{1}$

Neste contexto, as unidades hospitalares responsáveis pela produção de alimentos merecem atenção especial.Entre aquelas identificadas como sendo de risco, encontra-se o lactário, uma área restrita e exclusiva destinada ao preparo, higienização e distribuição de fórmulas infantis e complementares, para alimentação de recém-nascidos e de pacientes pediátricos. ${ }^{2}$ Os neonatos de baixo peso, ao nascer, são mais vulneráveis às DTA, principalmente pela imaturidade do sistema intestinal e imunológico, ${ }^{3}$ e a permanência deles em unidades de cuidados intensivos neonatais agravam essa exposição.

$\mathrm{O}$ aleitamento materno exclusivo deve ser encorajado até os 6 meses de vida, no entanto, algumas situações clínicas contraindicam essa prática. Nesses casos, as fórmulas infantis são indicadas em substituição total ou parcial do leite humano para crianças presentaron ausencia de coliformes a $45^{\circ} \mathrm{C}$, estafilococos coagulasa positivos y Salmonella sp. Las muestras Coliformes a $35{ }^{\circ} \mathrm{C}$ no excedieron los valores permitidos por la ley. La temperatura media del agua en los turnos de mañana y tarde fueron, respectivamente, $91,5^{\circ} \mathrm{C}$ y $89^{\circ} \mathrm{C}$ y el IS fue de 0,98 . La temperatura media del refrigerador fue de $2,5^{\circ} \mathrm{C}$ y $3,1^{\circ} \mathrm{C}$ y IS de 0,99. Conclusiónes: Se demostró que las muestras de agua y las muestras de fórmulas infantiles eran adecuadas para el consumo humano. El IS obtenido mostró grado satisfactorio de cumplimiento de los requisitos de la legislación actual. El seguimiento de estos pasos es fundamental para garantizar la calidad de las fórmulas producidas.

Palabras clave: Seguridad alimentaria y nutricional; Conservación de alimentos.

em risco nutricional, com a finalidade de atender suas necessidades de nutrição. ${ }^{4}$

As fórmulas infantis em pó não são estéreis e, durante sua reconstituição, podem ser contaminadas por várias espécies de bactérias. Dentre elas, a Cronobacter sp é uma das espécies mais prejudiciais, uma vez que pode causar sepse, meningite e enterocolite ulcerativa em recém-nascidos prematuros. ${ }^{5}$

A adoção de boas práticas, como o preparo e o armazenamento das fórmulas infantis de forma correta podem reduzir os riscos de contaminação microbiana e minimizar a incidência de surtos de DTA.

A reconstituição das fórmulas infantis em pó deve ser feita com água fervida e resfriada à temperatura superior a $70{ }^{\circ} \mathrm{C} .6,7$ As fórmulas infantis reconstituídas podem ser armazenadas por, no máximo, $24 \mathrm{~h}$ em geladeira exclusiva com temperatura entre 2 e $8{ }^{\circ} \mathrm{C} .{ }^{8} \mathrm{O}$ monitoramento das temperaturas nestas etapas possibilita, também, avaliar os processos e aplicar, de forma imediata, as ações corretivas necessárias. ${ }^{9}$

O objetivo deste estudo foi avaliar a qualidade microbiológica e identificar o grau de segurança das fórmulas infantis preparadas no lactário de um hospital universitário do Estado do Rio de Janeiro, por meio de análises microbiológicas e da utilização do índice de segurança (IS) com base nas temperaturas da água de reconstituição das fórmulas infantis em pó e das temperaturas da geladeira de armazenamento das fórmulas reconstituídas.

\section{Materiais e métodos}

Trata-se de um estudo descritivo, com delineamento transversal, realizado no lactário do Hospital Universitário Pedro Ernesto (HUPE), no Estado do Rio 
de Janeiro, no período de setembro de 2015 a março de 2016.

\section{Análises microbiológicas}

Foram selecionadas aleatoriamente amostras de fórmulas infantis reconstituídas e amostras de água utilizadas na reconstituição de fórmulas infantis em pó para o preparo de mamadeiras. Essas amostras foram coletadas uma vez por semana, perfazendo um total de 56 amostras no período estudado, sendo 28 amostras de fórmulas reconstituídas e 28 amostras de água filtrada proveniente da rede pública de abastecimento. As amostras foram acondicionadas em frascos estéreis, identificadas e transportadas em caixa térmica até o laboratório de bacteriologia (LABAC) do próprio hospital, em um prazo de até 2 horas.

As análises microbiológicas foram realizadas de acordo com a metodologia descrita no Manual de Métodos de Análises Microbiológicas de Alimentos ${ }^{10}$ e no Compendium of Methods for the Microbiological Examination of Foods.11 Os resultados foram expressos segundo as determinações da Resolução RDC nº 12 Regulamento técnico sobre padrões microbiológicos para alimentos. Especificamente para este grupo de alimentos, o regulamento preconiza a realização de análises microbiológicas para quantificação de coliformes a $35^{\circ} \mathrm{C}$ e Bacillus cereus e análise para verificar presença ou ausência de coliformes a $45^{\circ} \mathrm{C}$, estafilococos coagulase positiva e Salmonella sp. Para a água de envase utilizada no preparo de mamadeiras e similares devem ser quantificados coliformes a $35^{\circ} \mathrm{C}$, bactérias aeróbias mesófilas totais e Pseudomonas aeruginosa. ${ }^{12}$ Entretanto, por falta de meio de cultura especifico (ágar cetrimidi) em função da crise financeira, não foi possível analisar Pseudomonas aeruginosa em amostras de água em todo período estudado e Bacillus cereus nas amostras de fórmulas infantis reconstituídas no mês de março de 2016.

\section{Segurança higiênico-sanitária}

As temperaturas da água de reconstituição de fórmulas em pó e da geladeira de armazenamento das fórmulas reconstituídas foram aferidas diariamente em dois momentos, de manhã e de tarde, antes de cada etapa do preparo. Para reconstituição das fórmulas em pó, foi utilizada a água do filtro proveniente da rede de abastecimento público, previamente fervida. A geladeira utilizada para armazenamento das fórmulas reconstituídas é dedicada exclusivamente para este fim.
Para aferir a temperatura da água de reconstituição utilizou-se termômetro digital do tipo espeto, modelo 6132 , com escala de -50 a $300{ }^{\circ} \mathrm{C}$ e, para aferir a temperatura da geladeira, o termômetro digital interno/ externo, modelo 7666.02.0.00, com escala de $-20{ }^{\circ} \mathrm{C}$ a $70^{\circ} \mathrm{C}$, ambos da marca Incoterm, calibrados e higienizados com álcool 70\%. Os dados foram registrados em formulários próprios e monitorados pela nutricionista do setor.

O grau de segurança higiênico-sanitária das fórmulas infantis foi determinado por meio do índice de segurança (IS), proposto por Kawasaki e colaboradores..$^{13}$ O IS é representado pela relação entre o número de aferições de temperaturas que atenderam à legislação vigente e o total de aferições realizadas no período do estudo. Este índice pode variar de 0 a 1,0 e os valores mais próximos de 1,0 representam maior grau de segurança higiênico-sanitária do alimento. ${ }^{13}$

Os dados foram expressos em média e desvio padrão, considerando duas aferições diárias. A média foi comparada com os respectivos parâmetros estabelecidos pelas legislações vigentes. Para comparar as médias de temperaturas entre os dois turnos, foi utilizado teste $t$, adotando $\mathrm{p} \leq 0,05$ como nível de significância. Foi calculado IS para cada etapa do processo estudado.

\section{Resultados}

\section{Análises microbiológicas}

Com base nos critérios estabelecidos na RDC $n^{\circ} 12 / 2001$, as amostras analisadas foram classificadas em adequadas e inadequadas para consumo humano em relação às condições sanitárias. ${ }^{12}$

A avaliação microbiológica em amostra representativa das preparações realizadas em uma sessão de manipulação, para fórmulas infantis, deve ter ausência de coliformes a $45^{\circ} \mathrm{C}$, estafilococos coagulase positiva e Salmonellasp, e até $10 \mathrm{NMP} / \mathrm{mL}$ de coliformes a $35^{\circ} \mathrm{C}$. A água deve ter ausência de coliformes a $35^{\circ} \mathrm{C} / \mathrm{mL}$ e até $5 \times 102$ bactérias aeróbias mesófilas totais $/ \mathrm{mL}^{12}$

Os resultados das análises microbiológicas da água utilizada na reconstituição das fórmulas infantis em pó, no período de setembro de 2015 a março de 2016, estão descritos na Tabela 1. Todas as amostras de água apresentaram ausência de coliformes a $35^{\circ} \mathrm{C} / \mathrm{mL}$ e contagem de bactérias aeróbias mesófilas totais abaixo dos valores permitidos pela legislação. ${ }^{12}$

Na Tabela 2, encontram-se os resultados das análises microbiológicas de fórmulas infantis reconstituídas, no período de setembro de 2015 a março de 2016. Verifi- 


\section{Artigo original}

Tabela 1. Análises microbiológicas de água utilizada na reconstituição de fórmulas infantis em pó (set. 2015 - mar. 2016)

\begin{tabular}{|c|c|c|c|}
\hline Amostra & $\begin{array}{l}\text { Coliformes a } \\
350(\mathrm{NMP} / \mathrm{mL})\end{array}$ & $\begin{array}{c}\text { Aeróbios } \\
\text { mesófilos totais } \\
\text { (UFC/mL) }\end{array}$ & $\begin{array}{c}\text { Pseudomonas } \\
\text { aeruginosa }\end{array}$ \\
\hline $\mathrm{A} 1$ & Ausência & 1 & NR \\
\hline $\mathrm{A} 2$ & Ausência & 1 & NR \\
\hline A3 & Ausência & $<1$ & NR \\
\hline A4 & Ausência & $<1$ & NR \\
\hline A5 & Ausência & $<1$ & NR \\
\hline A6 & Ausência & $<1$ & NR \\
\hline A7 & Ausência & $<1$ & NR \\
\hline A8 & Ausência & $<1$ & NR \\
\hline A9 & Ausência & $<1$ & NR \\
\hline A10 & Ausência & $<1$ & NR \\
\hline A11 & Ausência & $<1$ & NR \\
\hline $\mathrm{A} 12$ & Ausência & $<1$ & NR \\
\hline $\mathrm{A} 13$ & Ausência & $<1$ & NR \\
\hline A14 & Ausência & $<1$ & NR \\
\hline A15 & Ausência & $<1$ & NR \\
\hline A16 & Ausência & $<1$ & NR \\
\hline A17 & Ausência & $<1$ & NR \\
\hline A18 & Ausência & $<1$ & NR \\
\hline A19 & Ausência & $<1$ & NR \\
\hline $\mathrm{A} 20$ & Ausência & $<1$ & NR \\
\hline $\mathrm{A} 21$ & Ausência & $<1$ & NR \\
\hline A22 & Ausência & $<1$ & NR \\
\hline A23 & Ausência & $<1$ & NR \\
\hline $\mathrm{A} 24$ & Ausência & $<1$ & NR \\
\hline A25 & Ausência & $<1$ & NR \\
\hline A26 & Ausência & $<1$ & NR \\
\hline A27 & Ausência & $<1$ & NR \\
\hline A28 & Ausência & $<1$ & NR \\
\hline
\end{tabular}

Legenda: A: água de reconstituição de fórmula infantil em pó. NMP: número mais provável. UFC: unidade formadora de colônia. NR: não realizado. cou-se que, todas as amostras analisadas apresentaram ausência de coliformes a $45^{\circ} \mathrm{C}$, estafilococos coagulase positiva e Salmonella sp e, para coliformes a $35^{\circ} \mathrm{C}$, as amostras não ultrapassaram os valores permitidos pela legislação. ${ }^{12}$ Sendo assim, evidenciou-se que, tanto as amostras de água como as amostras de fórmulas infantis reconstituídas estavam adequadas para o consumo humano.

\section{Grau de segurança higiênico-sanitária}

Em relação às temperaturas da água de reconstituição, identificou-se que $98,1 \%$ apresentaram valores acima de $70{ }^{\circ} \mathrm{C}$. Dentre as temperaturas da geladeira de armazenamento de fórmulas reconstituídas, 99\% apresentaram valores entre 2 e $8^{\circ} \mathrm{C}$.

A Tabela 3 demonstra a média e desvio padrão das temperaturas da água de reconstituição de fórmulas infantis em pó estratificados por mês e por turno. Considerando o grau de variação em relação à média, observou-se que, no mês de setembro, no turno da manhã, a temperatura média da água foi inferior a 70 ${ }^{\circ} \mathrm{C}$. Nos demais meses e turnos analisados, as temperaturas médias da água estavam em conformidade com a legislação vigente.

As temperaturas médias no período analisado para os turnos manhã e tarde foram, respectivamente, 89 e $91,5{ }^{\circ} \mathrm{C}$. Com exceção do mês de novembro, todas as temperaturas médias aferidas no turno da tarde apresentaram-se mais elevadas quando comparadas com as temperaturas do turno da manhã.

Verificou-se diferença significativa entre as médias das temperaturas nos turnos da manhã e da tarde, no mês de dezembro $(\mathrm{p}=0,05)$. Nos demais meses, apesar de haver diferenças entre as temperaturas nos dois turnos, elas não foram estatisticamente significativas.

A Tabela 4 apresenta a média e desvio padrão das temperaturas da geladeira de armazenamento de fórmulas infantis reconstituídas por mês e por turno. Considerando esses valores, verificou-se que, no mês de setembro, no turno da tarde, a temperatura média da geladeira foi superior a $8^{\circ} \mathrm{C}$, caracterizando não conformidade com a RDC n ${ }^{\circ} 63 .^{8}$ Nos demais meses e turnos analisados, as temperaturas médias da água estavam em conformidade com a legislação vigente.

As temperaturas médias da geladeira para os turnos manhã e tarde foram, respectivamente, $2,5^{\circ} \mathrm{C}$ e $3,1^{\circ} \mathrm{C}$. Observou-se diferença significativa entre as médias das temperaturas nos turnos da manhã e da tarde, no mês de setembro $(\mathrm{p}<0,0001)$.

Os IS para as temperaturas da água de reconstituição 
Deborah R. Siqueira e col.. • Qualidade microbiológica e índice de segurança de fórmulas infantis preparadas em lactário hospitalar

Tabela 2. Análises microbiológicas de fórmulas infantis reconstituídas (set. 2015 - mar. 2016)

\begin{tabular}{|c|c|c|c|c|c|}
\hline Amostra & $\begin{array}{c}\text { Coliformes a } \\
35^{\circ} \mathrm{C}(\mathrm{NMP} / \mathrm{mL})\end{array}$ & $\begin{array}{c}\text { Coliformes a } 45^{\circ} \mathrm{C} \\
(\mathrm{NMP} / \mathrm{mL})\end{array}$ & $\begin{array}{l}\text { Bacillus cereus } \\
\text { (UFC/mL) }\end{array}$ & $\begin{array}{c}\text { estafilococcus } \\
\text { coagulase positivo } \\
\text { (UFC/mL) }\end{array}$ & $\begin{array}{l}\text { Salmonela sp } \\
\text { (UFC/mL) }\end{array}$ \\
\hline $\mathrm{FI} 1$ & $<0,3$ & Ausência & $<1$ & Ausência & Ausência \\
\hline $\mathrm{FI} 2$ & $<0,3$ & Ausência & $<1$ & Ausência & Ausência \\
\hline $\mathrm{FI3}$ & $<0,3$ & Ausência & $<1$ & Ausência & Ausência \\
\hline $\mathrm{FI} 4$ & $<0,3$ & Ausência & $<1$ & Ausência & Ausência \\
\hline $\mathrm{FI5}$ & $<0,3$ & Ausência & $<1$ & Ausência & Ausência \\
\hline $\mathrm{FI} 6$ & $<0,3$ & Ausência & $<1$ & Ausência & Ausência \\
\hline $\mathrm{FI7}$ & $<0,3$ & Ausência & $<1$ & Ausência & Ausência \\
\hline $\mathrm{Fl} 8$ & $<0,3$ & Ausência & $<1$ & Ausência & Ausência \\
\hline FI9 & $<0,3$ & Ausência & $<1$ & Ausência & Ausência \\
\hline $\mathrm{Fl} 10$ & $<0,3$ & Ausência & $<1$ & Ausência & Ausência \\
\hline $\mathrm{Fl} 11$ & $<0,3$ & Ausência & $<1$ & Ausência & Ausência \\
\hline $\mathrm{Fl} 12$ & $<0,3$ & Ausência & $<1$ & Ausência & Ausência \\
\hline $\mathrm{Fl} 13$ & $<0,3$ & Ausência & $<1$ & Ausência & Ausência \\
\hline $\mathrm{Fl} 14$ & $<0,3$ & Ausência & $<1$ & Ausência & Ausência \\
\hline $\mathrm{FI} 15$ & $<0,3$ & Ausência & $<1$ & Ausência & Ausência \\
\hline $\mathrm{Fl} 16$ & $<0,3$ & Ausência & $<1$ & Ausência & Ausência \\
\hline $\mathrm{FI} 17$ & $<0,3$ & Ausência & $<1$ & Ausência & Ausência \\
\hline $\mathrm{Fl} 18$ & $<0,3$ & Ausência & $<1$ & Ausência & Ausência \\
\hline $\mathrm{Fl} 19$ & $<0,3$ & Ausência & $<1$ & Ausência & Ausência \\
\hline $\mathrm{FI} 20$ & $<0,3$ & Ausência & $<1$ & Ausência & Ausência \\
\hline $\mathrm{FI} 21$ & $<0,3$ & Ausência & $<1$ & Ausência & Ausência \\
\hline $\mathrm{FI} 22$ & $<0,3$ & Ausência & $<1$ & Ausência & Ausência \\
\hline $\mathrm{Fl} 23$ & $<0,3$ & Ausência & $<1$ & Ausência & Ausência \\
\hline $\mathrm{Fl} 24$ & $<0,3$ & Ausência & $<1$ & Ausência & Ausência \\
\hline $\mathrm{FI} 25$ & $<0,3$ & Ausência & NR & Ausência & Ausência \\
\hline $\mathrm{FI} 26$ & $<0,3$ & Ausência & NR & Ausência & Ausência \\
\hline $\mathrm{FI} 27$ & $<0,3$ & Ausência & NR & Ausência & Ausência \\
\hline $\mathrm{Fl} 28$ & $<0,3$ & Ausência & NR & Ausência & Ausência \\
\hline
\end{tabular}

Legenda: Legenda: FI: fórmula infantil reconstituída. NMP: número mais provável. UFC: unidade formadora de colônia. NR: não realizado. 


\section{Artigo original}

e para as temperaturas da geladeira foram respectivamente, 0,98 e 0,99 (Tabela 5). Para cálculo do IS, foram consideradas as aferições que atenderam às legislações como sendo aquelas cujas temperaturas da água estavam acima de $70{ }^{\circ} \mathrm{C}$ e as temperaturas da geladeira abaixo de $8{ }^{\circ} \mathrm{C}$. $^{6-8}$

\section{Discussão}

As fórmulas infantis devem oferecer às crianças energia e nutrientes adequados para seu crescimento, desenvolvimento e recuperação do estado nutricional. Contudo, também devem estar seguras do ponto de vista higiênico-sanitário. Para isso os alimentos devem ser armazenados, preparados e distribuídos de forma a garantir ausência de risco de contaminação microbiana em todo processo de manipulação. ${ }^{14}$

A presença de microrganismos pode ter origem a partir da matéria-prima contaminada, armazenamento inadequado, transporte impróprio ou contaminação durante a preparação, especialmente na etapa de re-

Tabela 3. Temperaturas médias, desvio-padrão, valor de $p$ da água de reconstituição das fórmulas infantis em pó (set. 2015 - mar. 2016)

\begin{tabular}{ccccc}
\hline \multirow{2}{*}{ Meses } & \multicolumn{2}{c}{$\begin{array}{c}\text { Temperatura média }\left({ }^{\circ} \mathrm{C}\right) \\
\text { Desvio padrão/turno }\end{array}$} & \multirow{2}{*}{ P valor } \\
\cline { 2 - 3 } & \multicolumn{1}{c}{ Manhã } & Tarde & \\
\hline Setembro & $78,8 \pm 17,5$ & $87,6 \pm 15,4$ & 0,06 \\
\hline Outubro & $87,8 \pm 10,6$ & $91,7 \pm 8,4$ & 0,08 \\
\hline Novembro & $94,3 \pm 9,2$ & $93,4 \pm 8,9$ & 0,64 \\
\hline Dezembro & $90,9 \pm 9,9$ & $94,9 \pm 7,2$ & $0,05^{*}$ \\
\hline Janeiro & $90,6 \pm 9,0$ & $90,7 \pm 8,8$ & 0,96 \\
\hline Fevereiro & $88,3 \pm 8,7$ & $89,4 \pm 10,3$ & 0,60 \\
\hline Março & $92,0 \pm 9,1$ & $93,1 \pm 8,9$ & 0,60 \\
\hline Média ${ }^{\circ} \mathrm{C} /$ & 89,0 & 91,5 & \\
\hline turno & & & \\
\hline
\end{tabular}

* Diferença significativa com uso do Teste t. Significância estatística $p \leq 0,05$. constituição das fórmulas em pó. ${ }^{15}$

Este estudo evidenciou que todas as amostras de água e amostras de fórmulas infantis reconstituídas estavam adequadas para o consumo humano, cujas análises microbiológicas encontravam-se dentro dos valores estabelecidos pela legislação vigente. Em contrapartida, um estudo realizado por Cairo e colaboradores ${ }^{16}$ em lactários de hospitais públicos e privados da cidade de Salvador isolou bactérias patogênicas a partir de 17 (18,7\%) amostras de fórmulas infantis, sendo que as bactérias mais frequentes foram: Bacillus sp, Staphylococcus sp, Pseudomonas sp, Enterobacter cloacae e Pseudomonas aeruginosa.

Horita e colaboradores, ${ }^{17}$ em uma pesquisa realizada em seis unidade hospitalares em Campinas, identificaram que amostras de fórmulas infantis reconstituídas apresentaram microrganismos em níveis que variaram de $<1 \mathrm{UFC} / \mathrm{mL}$ a 6,3x105 UFC/mL para aeróbios mesófilos e ausência de enterobactérias totais, Escherichia coli e coliformes totais em $1 \mathrm{~mL}$ de amostra. Somente um

Tabela 4. Temperaturas médias, desvio-padrão e valor de p da geladeira de armazenamento de fórmulas infantis reconstituídas (set. 2015 - mar. 2016)

\begin{tabular}{|c|c|c|c|}
\hline \multirow[t]{2}{*}{ Meses } & \multicolumn{2}{|c|}{$\begin{array}{c}\text { Temperatura média }\left({ }^{\circ} \mathrm{C}\right) \\
\text { Desvio padrão/turno }\end{array}$} & \multirow[t]{2}{*}{ P valor } \\
\hline & Manhã & Tarde & \\
\hline Setembro & $3,1 \pm 1,3$ & $6,5 \pm 1,7$ & $<0,0001^{*}$ \\
\hline Outubro & $2,7 \pm 1,8$ & $3,3 \pm 2,3$ & 0,12 \\
\hline Novembro & $3,1 \pm 2,1$ & $3,1 \pm 1,8$ & 0,95 \\
\hline Dezembro & $2,3 \pm 1,7$ & $2,1 \pm 1,3$ & 0,61 \\
\hline Janeiro & $2,0 \pm 1,2$ & $1,7 \pm 1,4$ & 0,50 \\
\hline Fevereiro & $2,8 \pm 1,4$ & $2,5 \pm 1,3$ & 0,48 \\
\hline Março & $1,8 \pm 1,2$ & $2,0 \pm 1,5$ & 0,55 \\
\hline $\begin{array}{l}\text { Média }{ }^{\circ} \mathrm{C} / \\
\text { turno }\end{array}$ & 2,5 & 3,1 & \\
\hline
\end{tabular}

Tabela 5. IS das etapas de processo (set. 2015 - mar. 2016)

\begin{tabular}{cccc}
\hline Etapa & NMM & NTM & IS \\
\hline Temperatura da água de reconstituição de fórmulas em pó & 404 & 412 \\
\hline Temperatura da geladeira de armazenamento de fórmulas reconstituídas & 408 & 412 & 0,98
\end{tabular}

NMM: número de aferições que atenderam a legislação. NTM: número total de aferições. IS: índice de segurança. 
lactário (17\%) apresentou os menores valores de contagens microbiológicas para todos os microrganismos avaliados. Com relação aos coliformes totais e Escherichia coli, verificou-se que $100 \%$ das amostras estavam de acordo com a RDC $n^{\circ} 12 / 2001$, o que corrobora os achados deste estudo.

O fato de não ter sido feita a pesquisa para Pseudomonas aeruginosa em amostras de água representa uma limitação ao estudo, entretanto destaca-se que no período entre 2009 e 2012 foram realizadas, no hospital, 164 pesquisas do microrganismo, uma média de 41 análises por ano e, em todas as amostras, não foi encontrado Pseudomonas aeruginosa, demonstrando baixa incidência deste microrganismo em água da rede de abastecimento devidamente tratada. Além disso, por ser um microrganismo oportunista que raramente causa doença via sistema digestivo, tendo preferência pelo trato respiratório, tal limitação não compromete os objetivos deste estudo, considerando ainda que os demais protocolos foram seguidos.

Alguns fatores influenciam diretamente na sobrevivência ou multiplicação dos microrganismos no alimento, dentre eles a temperatura da água de reconstituição e da geladeira de armazenamento, que têm papel fundamental na inocuidade das fórmulas infantis. ${ }^{6,7}, 8$

De acordo com o estudo de análise de risco da Organização das Nações Unidas para Alimentação e Agricultura, a temperatura da água de reconstituição de fórmulas em pó igual ou superior a $70^{\circ} \mathrm{C}$ promove a destruição de microrganismos como Cronobacter sp e Salmonella e os métodos adequados de conservação de fórmulas reconstituídas minimizam os possíveis riscos de contaminação para lactentes. ${ }^{6}$

As temperaturas médias da água de reconstituição de fórmulas em pó, aferidas neste estudo, estavam acima de $70{ }^{\circ} \mathrm{C}$ e, nos turnos da manhã e tarde foram respectivamente, 89 e $91,5^{\circ} \mathrm{C}$. Entretanto, ao considerar o grau de variação em relação à média, identificou-se no mês de setembro, no turno da manhã, que a temperatura média da água foi inferior a $70^{\circ} \mathrm{C}$. Esta oscilação na temperatura da água de reconstituição indica a necessidade de aprimorar a capacitação dos manipuladores e resgatar as rotinas e procedimentos operacionais padronizados implantadas no setor.

Em relação à temperatura da geladeira verificou-se que, também no mês de setembro, no turno da tarde, a temperatura média da geladeira estava superior a $8{ }^{\circ} \mathrm{C}$. Essa não conformidade demonstra a necessidade de avaliar o funcionamento do equipamento, elaborar plano de manutenção preventiva, assim como observar a frequência de abertura da porta da geladeira.

O IS é uma ferramenta que integra o método para a determinação da efetividade do controle higiênico-sanitário e avalia o grau de cumprimento das metas propostas, considerado como garantia da produção de alimentos. ${ }^{9}$

De acordo com este método de análise de qualidade sanitária, os índices mais próximos de 1,0 expressam menor risco sanitário. ${ }^{9}$ Os IS para as temperaturas da água de reconstituição e para as temperaturas da geladeira foram respectivamente, 0,98 e 0,99. Assim, os resultados deste estudo demonstraram que, nestas etapas, o grau de segurança higiênico-sanitária foi alto, indicando controle de qualidade eficaz e monitoramento adequado nas etapas de processo estudadas.

Rennó e colaboradores ${ }^{9}$ analisaram as temperaturas de 38 equipamentos, sendo 23 de conservação de alimentos a frio e 15 destinados à distribuição de alimentos prontos para consumo em Unidade produtora de refeições de um complexo hoteleiro de grande porte, na região Centro-Oeste do Brasil. Observaram que o IS geral foi 0,19 , considerado muito aquém do valor encontrado neste estudo e revelou insuficiência no grau de cumprimento das metas propostas para as temperaturas dos equipamentos de conservação e distribuição de alimentos, apontando baixo nível de controle higiênico-sanitário.

Um estudo realizado na França, por Rosset e colaboradores ${ }^{18}$ avaliou as condições de temperatura no preparo e armazenamento de fórmulas infantis em pó para crianças internadas em unidades de cuidados neonatais e associou o impacto destes resultados com o crescimento potencial da Enterobacter sp. Os autores concluíram que o incremento no crescimento bacteriano foi o resultado da combinação de diferentes parâmetros, como: temperatura inicial da fórmula infantil, temperatura do ambiente de manipulação, temperatura do armazenamento à frio e temperatura e tempo do reaquecimento das fórmulas. ${ }^{18}$

\section{Conclusões}

Este estudo mostrou que, tanto as amostras de água como as amostras de fórmulas infantis estavam adequadas para o consumo humano. O IS revelou grau satisfatório de cumprimento das exigências da legislação vigente. Entretanto, estes resultados não dispensam a necessidade de adoção de rotina sistemática de manutenção de equipamentos, orientação e treinamentos periódicos dos manipuladores.

$\mathrm{O}$ uso de indicadores como o IS é fundamental 


\section{Artigo original}

no monitoramento das etapas de processo, pois estes permitem identificar possíveis falhas e etapas críticas, além de priorizar ações corretivas, minimizando os riscos de contaminação, assegurando alimentação de boa qualidade aos usuários do hospital.

\section{Referências}

1. Brasil. Ministério da Saúde. Secretaria de Vigilância em Saúde (SVS). Surtos de doenças transmitidas por alimentos no Brasil, 2007-2016. Junho de 2016. Disponível em: <http://portalarquivos.saude.gov.br/images/pdf/2016/junho/08/Apresenta---o-Surtos-DTA-2016.pdf> Acesso em: 10 jan. 2017.

2. Santos MIS, Tondo EC. Determinação dos perigos e pontos críticos de controle para implantação de sistema APPCC. Rev. Nutr. Campinas. 2000;13(3):211-22.

3. Mardaneh J, Soltan-Dallal MM. Isolation and Identification of E. cowanii from Powdered Infant Formula in NICU and Determination of Antimicrobial Susceptibility of Isolates. Iran J Pediatr. 2014;24(3):261-6.

4. Brasil. Agência Nacional de Vigilância Sanitária (ANVISA). Resolução da Diretoria Colegiada n 43, de 19 de setembro de 2011. Regulamento técnico para fórmulas infantis para lactentes. Diário Oficial da União. Brasília/DF, 2011a. Disponível em: <https://www.saude.rj.gov.br/comum/code/MostrarArquivo. php?C=MTk4MQ\%2C\%2C > Acesso em: 10 jan. 2017.

5. Silano M, Paganin P, Davanzo R. Time for the $70^{\circ} \mathrm{C}$ water precautionary option in the home dilution of powdered infant formula. Ital J Pediatr. 2016;42:17.

6. World Health Organization. How to Prepare Formula for Bottle-Feedingat Home. Geneva: World Health Organization; 2007. Disponível em: <http://www.who.int/foodsafety/document_centre/PIF_Bottle_en.pdf > Acesso em: 10 jan. 2017.

7. Brasil. Agência Nacional de Vigilância Sanitária (ANVISA). Resolução da Diretoria Colegiada n45, de 19 de setembro de 2011. Regulamento Técnico para fórmulas infantis para lactentes destinadas a necessidades dietoterápicas específicas e fórmulas infantis de seguimento para lactentes e crianças de primeira infância. Diário Oficial da União. Brasília/DF, 2011b. Disponível em: <http:// portal.anvisa.gov.br/documents/33916/394219/Resolu\%25C3\%25A7\%25C3\%25A3o\%2BRDC\%2B45_2014_Altera\%2BRDC\%2B42_2011_.pdf/fa71a5d9-f852-42c8-b10e7f71 fefffa80?version=1.0> Acesso em: 10 jan.2017.

8. Brasil. Agencia Nacional de Vigilância Sanitária (ANVISA). Resolução da Diretoria Colegiada n 63. 6 de julho de 2000.
Regulamento técnico: Requisitos Mínimos exigidos para a Terapia de Nutrição Enteral. Ministério da saúde. Brasília/DF, 2000. Disponível em: <https://www.univates.br/unianalises/media/imagens/Anexo_X_61948_10.pdf> Acesso em: 10 jan.2017.

9. Rennó FF, Weber ML, Gonçalves ES. Análise do nível de segurança das refeições produzidas em complexo hoteleiro de grande porte na região centro-oeste do Brasil. J Health Sci Inst. 2013;31(3):296-300.

10. Silva Jr EA. Manual de controle higiênico-sanitário em serviços de alimentação. 7. ed. São Paulo: Varela; 2014. 693 p.

11. American Public Health Association. Compendium of Methods for the Microbiological Examination of foods. 4th ed. Washington: APHA; 2001. 676 p.

12. Brasil. Agencia Nacional de Vigilância Sanitária (ANVISA). Resolução da Diretoria Colegiada n 12, de 2 de janeiro de 2001. Regulamento Técnico sobre padrões microbiológicos para alimentos. Diário Oficial da União. Brasília/DF, 2001. Disponível em: <http://portal.anvisa.gov.br/documents/33880/2568070/ RDC_12_2001.pdf/15ffddf6-3767-4527-bfac-740a0400829b> Acesso em 10 jan.2017.

13. Kawasaki VM, Cyrillo DC, Machado FMS. Custo-efetividade da produção de refeições coletivas sob o aspecto higiênico-sanitário em sistemas cook-chill e tradicional. Rev Nutr. 2007;20(2):129-38.

14. Codex Alimentarius Commission. Code of hygienic practice for powdered formulae for infants and young children. CAC/RCP 66 - 2008. 2008. 29 p. Technical Report, 66. Washington, 2008, 29 p. Disponível em: <http://www.fao.org/fao-who-codexalimentarius/standards/list-of-standards/en/> Acesso em: 20 nov. 2016.

15. Ribas MF, Lavarda SCS. Avaliação das Condições Higiênico-Sanitárias em Lactário de Hospital Particular. In: Simpósio de Segurança Alimentar e Saúde, 5., 2015. Bento Gonçalves, Rio Grande do Sul, 2015. Disponível em: <http://www.ufrgs. br/sbctars-eventos/gerenciador/painel/trabalhosversaofinal/ SAL111.pdf.> Acesso em: 10 jan. 2017.

16. Cairo RC, Silva LR, Andrade CF, et al. Bacterial contamination in milk kitchens in pediatric hospitals in Salvador, Brazil. Braz J Infect Dis. 2008;12(3):217-21.

17. Horita HC, Cardozo GM, Imazaki FT, et al. Avaliação microbiológicas de formulações lácteas infantis preparadas em lactários hospitalares do Município de Campinas (SP) e Região. In: Congresso Interinstitucional de Iniciação Científica, 8., 2014, Campinas. Anais. Campinas: RE14232, 2014.

18. Rosset $P$, Noel V, Morelli E. Time-temperature profiles of infant milk formula in hospital sand analysis of Enterobacter sakazakii growth. Food Control. 2007;18:1412-8. 